\title{
Implementasi Good Ngo Governance Pada Lembaga Swadaya (LSM) Lokal
}

\author{
Lussy Sandovi', Eka Vidya Putra ${ }^{2}$ \\ 1,2 Universitas Negeri Padang \\ email: lussysandovi27@gmail.com
}

\begin{abstract}
Abstrak
YCM-M dan LP2M merupakan dua diantara banyaknya Lembaga Swadaya Masyarakat (LSM) Lokal yang berusaha mewujudkan good NGO governance. Untuk mewujudkannya, kedua LSM ini mendirikan Konsorsium Pengembangan Masyarakat Madani (KPMM). Selain untuk mendapat kepercayaan dari publik, hal itu juga membuat LSM tidak lagi dipandang sebelah mata karena selama ini LSM selalu menuntut pemerintah untuk melakukan good governance sementara LSM sendiri masih tertinggal jauh. Penelitian ini dianalisis menggunakan teori new institutional. Penelitian ini merupakan jenis penelitian kualitatif dengan tipe deskriptif. Hasil penelitian mengungkapkan, terdapat perbedaan antara YCM-M dan LP2M dalam menerapkan good NGO governance.YCM-M tidak selalu menerapkan prinsip non partisan, sementara LP2M selalu menerapkan itu. YCM-M belum sepenuhnya menerapkan prinsip transparansi dan akuntabilitas sedangkan LP2M telah matang dalam menerapkannya. YCM-M selalu melaksanakan prinsip kesetaraan gender namun LP2M masih kurang matang dalam menerapkannya. Terakhir, kedua LSM telah melaksanakan prinsip partisipatif.
\end{abstract}

Kata Kunci: YCM-M, LP2M, Implementasi, Good governance

Abstract
YCM-M and LP2M are two of the many local non-governmental organizations that are trying to realize good ngo governance. To make it happen, these two non-governmental organizations established KPMM. In addition to gaining trust from the public, it also makes $N G O s$ not underestimated because so far NGOs have always demanded the government to do good governance while NGOs themselves are still far behind. This study was analyzed using the new institutional theory. This research is a type of qualitative research with descriptive research type. The results of the study revealed, there is a difference between YCM-M and $L P 2 M$ in applying good NGO governance. YCM-M don't always apply non partisan principles, while LP2M always applies it. YCM-M has not fully applied the principles of accountability and transparency, while LP2M has matured in implementing it.YCM-M always carry out the principle of gender equality, while LP2M is still lacking in implementing it. Lastly, both NGOs have implemented participatory principles.

Keywords: YCM-M, LP2M, Implementasi, Good governance 


\section{Pendahuluan}

Good NGO governance merupakan suatu mekanisme yang mengatur tata kelola LSM sesuai dengan prinsip-prinsip good governance agar LSM bersifat transparan dan terbebas dari korupsi. Prinsip good governance dalam Peraturan Pemerintah No. 101 Tahun 2000 terdiri dari profesionalitas, akuntabilitas, transparansi, pelayanan prima, demokrasi dan partisipasi, efisiensi dan efektifitas dan supremasi hukum. Sebagai sebuah organisasi yang selalu menutut pemerintah agar menjalankan prinsip good governance pada akhirnya LSM juga dituntut untuk melakukan good NGO governance. Tuntutan itu juga disebabkan oleh berbagai kondisi lain yaitu munculnya banyak LSM di Indonesia dan donor internasional, serta berlakuknya UU No. 16 Tahun 2001 tentang Yayasan.

Dalam merespon isu good governance, maka beberapa LSM (diantaranya YCMM- dan LP2M) yang ada di Sumatera Barat mendirikan Konsorsium Pengembangan Masyarakat Madani (KPMM) pada 12 November 1999 sebagai sebuah wadah untuk berkumpul dan berusaha meningkatkan good $N G O$ governance. KPMM didirikan dengan tujuan agar dapat merubah perspektif masyarakat terhadap LSM yang ada di Sumatera Barat dengan cara melakukan perbaikan dari dalam LSM itu sendiri, sehingga ketransparansian LSM dapat terwujud dan mendapat kepercayaan dari masyarakat. Keseriusan KPMM dalam merespon isu good NGO governance dituangkan dalam nilai-nilai dasar KPMM. Dapat dilihat dengan disepakatinya 10 nilai dasar LSM yaitu : (1) non-partisan, (2) professional, (3) independent, (4) transparan, (5) akuntabilitas, (6) kesetaraan dan keadilan jender, (7) anti diskriminatif, (8) kerelawanan, (9) egaliter, dan (10) demokrasi. ${ }^{1}$ Hal ini merupakan turunan dari good governance yang kemudian menjadi acuan bagi anggota KPMM untuk melakukan good NGO governance.

Maka dalam penelitian ini, peneliti ingin mendeskripsikan implementasi good NGO governance di dua LSM sebagai pendiri KPMM sekaligus sebagai LSM terlama yang masih eksis di Sumatera Barat dengan judul penelitian "Implementasi Good NGO Governance Pada Lembaga Swadaya Masyarakat (LSM) Lokal Studi Kasus : Yayasan Citra Mandiri Mentawai (YCMM) dan Lembaga Pengkajian dan Pemberdayaan Masyarakat (LP2M)”.

\section{Metode Penelitian}

\section{ImformanPenelitian}

Informan pada penelitian ini merupakan informan kunci yang memiliki pengetahuan mendalam tentang permasalahan yang dikaji peneliti.Infroman kunci yang dimaksud dalam penelitian ini adalah Direktur YCM-M dan LP2M, Staff ataupun Personil YCM-M dan LP2M yang telah berpengalaman dan mengetahui perjalanan masing-masing LSM.

\section{TeknikPengumpulan Data}

Penelitian ini merupakan penelitian kualitatif dengan menggunakan tipe penelitian deskriptif. Tipe penelitian yang digunakan peneliti adalah studi kasus (case study) merupakan tipe penelitian yang berusaha menyelidiki fenomena dalam konteks kehidupan nyata, antara fenomena dan konteksnya saling berkaitan dan tidak berpisah dan tidak memanfaatkan banyak bukti atau informasi untuk pencarian datanya. ${ }^{2}$ Data diperoleh dengan menggunakan metode pengumpulan data partisipasipasif, yaitu peneliti dating dan melihat langsung kelokasi penelitian untuk memperoleh data yang diinginkan namun tidak terlibat langsung

\footnotetext{
${ }^{1}$ AD ART KPMM Tahun 2010.

${ }^{2}$ Robert K. Yin, "Studi Kasus, Desain dan Metode", Rajawali Press, Jakarta, 1996, Hal. 18
} 
dalam setiap kegiatan anggota organisasi.Penelitian ini menggunakan metode wawancara berstruktur, yaitu peneliti menyiapkan pedoman wawancara terlebih dahulu serta menggunakan teknik wawancara mendalam (in depth interview) yaitu teknik pengumpulan data yang didasarkan pada percakapan secara intensif dengan satu tujuan.

\section{Triangulasi Data}

Peneliti melakukan triangulasi data dengan cara memberikan pertanyaan yang sama kepada informan yang berbeda. Hal ini dilakukan sampai terjadinya kejenuhan data sehingga data dapat dianggap telah valid.

\section{Teknik Analisis Data}

Dari berbagai data yang ditemukan, peneliti kemudian menganalis data dengan menggunakan model analisis interaktif Miles dan Huberman. Model analisis interaktif Miles danHuberman terdiri dari tiga komponen yakni reduksi data, display data dan coclusion atau penarikan kesimpulan.

\section{Hasil dan Pembahasan}

Dari 10 nilai dasar yang telah dirumuskan oleh KPMM untuk mewujudkan good NGO governance, maka dalam penelitian ini hanya membahas lima nilai dasar yaitu non partisan, transparansi, akuntabilitas, kesetaraan gender dan partisipatif. Lima nilai dasar ini merupakan nilai utama good NGO governance.

Pada dasarnya, baik YCM-M maupun LP2M memahami nilai-nilai tersebut dengan cara yang sama. Namun dalam pelaksanaannya terdapat perbedaan. Terkait penerapan nilai-nilai tersebut di YCM-M dan LP2M dapat dipahami sebagai berikut :

\section{Non Partisan}

Non Partisan merupakan sikap yang tidak berafiliasi, mendukung, berpartisipasi ataupun terlibat dengan partai politik. prinsip non partisan harus dimiliki oleh setiap LSM karena jika LSM terlibat dalam hal tersebut akan memungkinkan terjadinya konflik kepentingan bahkan terkadang sebagian orang menggunakan LSM sebagai alat untuk memperoleh kekuaasaan. Oleh sebab itu, LSM diharuskan tidak terlibat dalam setiap hal yang berhubungan dengan partai politik ataupun mencalonkan diri menjadi kepala daerah atau calon legislatif.

Dalam pelaksanaannya, YCMM tidak memihak terhadap kepentingan salah satu partai politik, tidak terlibat dalam aktivitas pemilihan kepala pemerintahan maupun caleg tapi hanya melakukan pendidikan politik.YCMM memandatkan personilnya untuk bergabung ke partai politik agar bisa duduk di DPRD maupun menjadi Kepala Daerah. Namun, YCM-M menggunakan partai politik sebagai alat atau kendaraan untuk memperoleh kekuasaan sehingga bisa mengubah kebijakan yang lebih berpihak kepada masyarakat Mentawai apabila mereka berhasil menduduki jabatan di pemerintahan. Dalam teori new institutional, YCM-M telah melakukan manipulasi dimana dia mengatakan tidak memihak ke partai politik namun tetap bergabung ke partai politik tersebut yang merupakan upaya untuk mencapai tujuan organisasi. Sementara LP2M melarang setiap personil untuk terlibat dalam hal yang berkaitan dengan politik praktis.

\section{Transparansi}


Transparansi merupakan sikap terbuka sebuah badan atau lembaga kepada masyarakat guna mendapatkan akses informasi yang benar, jujur dan adil, namun tetap melindungi hak-hak dasar dan kerahasiaan sebuah badan atau lembaga yang berkerja. ${ }^{3}$ Dalam pelaksanaannya, YCM-M memberikan laporan keuangan berdasarkan permintaan dari masyarakat itu sendiri.YCMM tidak menempel laporan keuangan di lembaga karena YCMM mengkhawatirkan apabila dipublikasi akan menyebabkan orang-orang untuk menjatuhkan organisasi YCM-M. Sementara LP2M selalu menyampaikan masalah keuangan sekali setahun pada masyarakat atau kelompok binaan melalui Rapat Anggota Tahunan (RAT). LP2M juga pernah menempel laporan keuangan di lembaga namun beberapa tahun belakangan tidak dilakukan lagi.

\section{Akuntabilitas}

Akuntabilitas merupakan keharusan bagi para pengambil keputusan dalam organisasi sektor publik, swasta dan masyarakat madani untuk memiliki pertanggungjawaban kepada publik. ${ }^{4}$ Agar akuntabilitas dapat terlaksana di LSM yang menjadi anggota KPMM, LSM harus membuka akses kepada masyarakat mitra atau perwakilanya dan donatur untuk mempertanyakan perencanaan, pelaksanaan, hasil dan pengelolaan keuangan yang dilakukan oleh lembaga.

Pada prinsipnya, YCM-M dan LP2M memiliki pandangan yang sama terkait akuntabilitas. Namun dalam menerapkannya, kedua LSM ini memiliki sedikit perbedaan. Kedua LSM membolehkan masyarakat maupun pihak lain untuk mempertanyakan perihal perencanaan, pelaksanaan, hasil dan pengelolaan keuangan LSM. Namun YCMM tidak membuka akses kepada publik untuk bisa mempertanyakan itu karena YCMM tidak mengumumkannya di website resmi miliki YCM-M. Sedangkan LP2M dulu pernah melaporkan perihal masalah keuangan di website, namun sekarang belum dilakukan lagi karena website resmi LP2M masih dalam tahap perbaikan.

\section{Kesetaraan Gender}

Kesetaraan gender di LSM dapat diartikan sebagai pemberian kesempatan yang sama baik kepada laki-laki atau perempuan dalam menempati posisi atau jabatan.Dalam pelaksanaannya, YCMM dan LP2M telah menerapkan prinsip kesetaraan gender dalam lembaganya. Namun perbedaannya terletak pada LP2M yang mengharuskan direkturnya perempuan karena LP2M merupakan sebuah lembaga yang berusaha meningkatkan keterwakilan perempuan untuk menjadi pemimpin.

\section{Partisipatif}

Partisipatif dalam LSM merupakan sebuah upaya yang melibatkan masyarakat agar terlibat dalam proses perencanaan program atau proses pengambilan keputusan yang ada di LSM. Dalam pelaksanaannya, YCMM dan LP2M telah menerapkan prinsip partisipatif dalam setiap perencanaan dan monev. YCMM juga melakukan pemetaan partisipatif untuk memetakan wilayah adat. Sementara LP2M membina masyarakat untuk menciptakan suatu produk dengan brand yang dinamakan "tek gadih".

\footnotetext{
${ }^{3}$ Lusi Herlina, "Pengembangan Transparansi Dan Akuntabilitas Di KPMM, Sumbar", Dalam Hamid Abidin dan Mimin Rukmini, Kritik dan Otokritik LSM: Membongkar Kejujuran dan Keterbukaan Lembaga Swadaya Masyarakat Indonesia, PIRAC, Ford Foundation dan Tifa, Jakarta, 2004, hlm. 197.

${ }^{4}$ Jubaidah, "Studi Tentang Pelaksanaan Pirnsip Good Governance dalam Pelayanaan Pertahanan di Kantor Badan Pertahanan Nasional Kota Balikpapan” Jurnal Ilmu Administrasi Negara, Vol.5, No.3, 2014
} 


\section{Analisis Teori}

New Institutional theory menekankan kepada dua hal yakni sebagai berikut :

\section{Organisasi dipengaruhi oleh lingkungan kelembagaan}

New Institutional theory memandang bahwa aktor, individu atau organisasi sangat dipengaruhi oleh kendala dan harapan lingkungan mereka masing-masing yang disebut institusi ${ }^{5}$. Sehingga perkembangan sebuah organisasi salah satunya ditentukan oleh lingkungan. YCMM dan LP2M lahir pada rentang waktu atau periode relatif sama yaitu ditahun 1990an. Pada saat itu rezim Orde Baru yang begitu otoriter, adanya represif negara dimana LSM hanya sebagai alat kendali pemerintah, LSM dikekang oleh pemerintah hanya untuk kepentingan politik semata. Terkait hal ini, ada beberapa hal yang perlu diperhatikan yaitu :

a. Bentuk Organisasi

Dalam bentuk organisasi, kedua LSM sangat dipengaruhi oleh Undang-Undang. LP2M awalnya merupakan sebuah LSM yang berbadan hukum yayasan. Namun pada akhirnya LP2M merubah bentuk organisasinya menjadi perkumpulan. Hal ini berbeda dengan YCM-M yang dari awal berdiri hinga saat ini masih berbentuk yayasan.

b. Tujuan Organisasi

Kedua LSM ini (YCMM dan LP2M ) merespon kondisi lingkungan kelembagaan dengan cara yang berbeda. YCMM memilih untuk menjadi LSM yang keras dan cenderung konflik dengan negara. Akan tetapi, LP2M lebih memilih lunak dengan negara. Perbedaan pilihan gerakan kedua LSM ini sangat berbeda karena disebabkan oleh tujuan organisasi yang juga berbeda. YCMM dalam hal ini berusaha memperjuangkan hak komunitas masyarakat Mentawai yang secara struktur dan kultur sangat tertindas atau diekspolitasi oleh negara. Sedangkan LP2M berusaha untuk menyetarakan hak-hak perempuan sebagai warga negara yang memiliki posisi yang setara dengan laki-laki. Jika dilihat dari tujuan organisasi YCMM dan LP2M, kedua organisasi ini cenderung tidak berubah dari awal berdiri hingga saat ini.

c. Strategi Organisasi

Lingkungan kelembagaan mengalami perubahan kembali dimana awalnya pemerintah begitu represif dan otoriter menjadi tidak terlalu represif lagi pada masa reformasi. Munculnya kebijakan desentralisasi membuat kedua LSM ini ternyata juga memilki perbedaan dalam menerapkan good NGO governance. YCM-M yang awalnya tidak mau bergabung ke partai politik, akhirnya memutuskan untuk terlibat di dalamnya. YCM-M melakukan itu karena melihat adanya peluang untuk mencapai tujuan organisasinya dengan cara memberi mandat kepada personil LSM untuk ikut mencalonkan diri dalam pilkada. Sementara LP2M tetap memilih tidak berpolitik praktis.

d. Mitra Strategis

Mitra strategis YCM-M merupakan pemerintah dalam lingkup Mentawai, sedangkan untuk Pemerintahan pusat YCM-M masih melakukan perlawanan karena banyak kebijakan pemerintah yang dirasa masih tidak memihak atau belum berupaya mensejahterakan masyarakat Mentawai. Sedangkan LP2M cenderung bermitra dengan Pemerintah terutama di tingkat Daerah dan LSM yang memiliki isu yang sama dengan LP2M.

${ }^{5}$ Sandhu, Swaran. "Neo-Institutional Theory". Encyclopedia of Strategic Communication (2015): 1-15 


\section{Organisasi sebagai aktor}

Organisasi sebagai aktor mempengaruhi lingkungan dengan cara melakukan manipulasi. Dengan berlakunya UU no. 16 Tahun 2001 tentang yayasan, LP2M yang awalnya berbentuk yayasan mengubah organisainya sebagai perkumpulan. Mereka menganggap LP2M sebagai yayasan masih memiliki kekurangan yaitu semangat demokrasinya berbeda dengan historikal anggotanya. Sementara YCM-M melihat tuntutan regulasi tidak begitu mempengaruhi organisasinya karena dari awal berdiri sampai saat ini YCM-M masih berbentuk yayasan.

YCM-M juga berusaha melakukan manipulasi dimana organisasi tersebut merupakan organisasi semi partisan karena terlibat dalam partai politik dan calon legislatif maupun kepala daerah, namun YCM-M mengatakan tidak mendukung partai politik tersebut namun menggunakan parpol sebagai kendaraan untuk memperoleh kekuasaan sehingga tujuan organisasi dapat tercapai.

Dari kedua analisis dua kondisi antara lingkungan kelembagaan dengan tujuan organisasi di atas dapat dilihat bagaimana lingkungan kelembagaan mempengaruhi bentuk organisasi. Namun disaat bersamaan, organisasi sebagai aktor juga mempengaruhi lingkungan untuk mencapai tujuannya. Hal inilah yang membuat adanya perbedaan penerapan good NGO governance pada kedua LSM.

\section{Penutup}

Terdapat perbedaan dalam menerapkan good NGO governance di kedua LSM. YCMM merupakan LSM yang partisan, sementara LP2M bersifat non partisan yang sesuai dengan salah satu prinsip dasar LSM. YCM-M belum sepenuhnya menerapkan prinsip akuntabilitas dan transparansi, sedangkan LP2M telah menerapkan seutuhnya. YCM-M telah menerapkan prinsip kesetaraan gender dengan baik, sementara LP2M masih kurang menerapkan prinsip ini. Terkahir, baik YCM-M maupun LP2M telah melaksanakan prinsip partisipatif. Perbedaan penerapan good NGO governance di kedua LSM disebabkan oleh perbedaan tujuan organisasi masing-masing LSM, karena setiap tindakan yang dilakukan oleh personil LSM merupakan upayanya untuk mencapai tujuan organisasi.

\section{Daftar Pustaka}

KPMM. (2010). AD ART KPMM Tahun 2010. Jakarta: KPMM

Jubaidah. (2014). "Studi Tentang Pelaksanaan Pirnsip Good Governance dalam Pelayanaan Pertahanan di Kantor Badan Pertahanan Nasional Kota Balikpapan" Jurnal Ilmu Administrasi Negara, Vol.5, No.3, 2014.

Lusi Herlina. (2004). "Pengembangan Transparansi Dan Akuntabilitas Di KPMM Sumbar", Dalam Hamid Abidin dan Mimin Rukmini, Kritik dan Otokritik LSM: Membongkar Kejujuran dan Keterbukaan Lembaga Swadaya Masyarakat Indonesia, PIRAC, Ford Foundation dan Tifa, Jakarta, 2004.

Robert K. Yin. (1996). Studi Kasus, Desain dan Metode. Jakarta: Rajawali Press

Swaran,Sandhu.(2015). "Neo-Institutional Theory", Encyclopedia of Strategic Communication. 